\title{
ТВОРЧЕСКОЕ МЫШЛЕНИЕ В СИСТЕМЕ ПОНЯТИЙ СОВРЕМЕННОЙ психологии
}

Общеизвестно, что 21-й век характеризуется быстрыми темпами развития, бурными изменениями, высоким темпом жизни, что требует от личности таких же быстрых и адекватных реакций, гибкости в восприятии проблемных ситуаций, продуктивности и эффективности в решении возникающих жизненных задач. В этом контексте приоритетным становиться обогащении науки как теоретическими и эмпирическими данными, так и разработка методов и механизмов развития активного воображения и творческого мышления, инициативных и творческих способностей личности.

Большой вклад в разработку проблем мышления, творческого мышления, творческой деятельности и способностей внесли в психологическую науку такие психологи, как Б.Г.Теплов, С.л.Рубинштейн, Б.Г.Ананьев, А.Г.Ковалев, К.К.Платонов, А.М.Матюшкин, В.Д.Шадриков, В.Н.Дружинин, М.А.Холодная, В.С.Юркевич, П.К.Энгельмейер, Я.А.Пономарев, О.К.Тихомиров, В.А.Терехов, П.Я.Гальперин ит.д.

Однако следует отметить, что, несмотря на это, в современной психологии отсутствует более или менее единая концепция о творческом мышлении, а значительная неясность в употреблении терминов создает существенные трудности при их использовании. Существует также неоднозначность в понимании творческого мышления и мышления в целом. Некоторые авторы рассматривают творческое мышления как вид мышления, однако более углубленный и многоаспектный анализ психологических теорий мышления выявляет иную сторону соотношения данных понятий, что в последующем изложении будет показано нами.

Для этого, прежде всего, необходимо рассмотреть и проанализировать такие терминологические понятия, как «творчество», «мышление», «творческое мышление», «интеллект», «креативность».

С самого начала следует разграничить термины «творчество» и "творческое мышление». Творчество является общенаучной категорией, а творческое мышление - психологическим понятием. При этом использование термина «творчество» в сугубо психологическом контексте обозначает, скорее всего, совокупность результатов творческого мышления, его условия, введение в практику продуктов творческого мышления. Творческое же мышление является качественно иной, специфической психической функцией, психическим процессом, суть которого заключается в особых механизмах протекания психической деятельности (Дружинин 2001).

В психологической литературе творческий процесс рассматривается как формирование новой реальности путем «созидательного разрушения», как акт создания нового. А именно особенности протекания творческого процесса как ментального акта будет являться объектом нашего анализа.

Известный психолог Я.А.Пономарев определяет творчество в широком смысле слова как «как механизм развития, как взаимодействие, ведущее к развитию", а творческое мышление как процесс в ситуации решения задачи, причем творческой задачей он считает задачу, 
решение которой невозможно получить путем логического вывода (Пономарев 1976; Torranсе 1965). С точки зрения ученого, творчество человека - это “одна из конкретных форм проявления механизма развития". В основу подхода к изучению данной конкретной формы положен принцип трансформации этапов развития явления в структурные уровни его организации и функциональные ступени дальнейших развивающих взаимодействий.

Многие авторы рассматривают творчество как деятельность, которая содержит неопределенность и отражает способность к продуктивности и новизне идей. Так, например, Тихомиров О.К. высказывает положение о том, что творчество - это «изучение функционального развития, новообразований, возникающих в ходе решения задачи» (Тихомиров 1975: 14), и указывает, что сами творческие способности под влиянием гипноза могут изменяться: «при внушении образа талантливого человека, происходит улучшение внимания, памяти и изобразительной деятельности, и наоборот, внушенный образ малограмотного человека резко уменьшает активность памяти и внимания» (Тихомиров 1975: 195).

При исследовании проблемы творческих способностей, следует учитывать три основных подхода. Согласно первому подходу, интеллект нужно расценивать как важное, но недостаточное условие для творчества, и первостепенную роль, при этом следует отдать мотивации, ценностям, а также таким личностным чертам, как когнитивная одаренность, чувствительность к проблемам, независимость в неопределенных и сложных ситуациях (А.Танненбаум, А.Олох, Д.Б.Богоявленская, А.Маслоу и др.). Причем придерживаясь этой точки зрения, Д.Б.Богоявленская, акцентирует внимание на существовании «креативно активного типа личности», которым обладают все новаторы и рационализаторы независимо от рода деятельности (Богоявленская 1971).
Второй подход предполагает рассматривать творческую способность как самостоятельный компонент или фактор, имеющий малую корреляцию с интеллектом личности. Наиболее интересной в этом контексте является «теория интеллектуального порога» Э.П.Торренса, согласно которой, если IQ ниже 115120, то интеллект и креативность образуют единый фактор, при IQ выше 120 творческая способность становится независимой величиной, т.е. нет творческих личностей с низким интеллектом, но есть интеллектуалы с низкой креативностью (Torrance 1965).

Сторонники третьего подхода полагают, что творческого процесса как особенной формы психической активности не существует, а высокая ступень развития интеллекта предполагает высокую степень развития творческих способностей, и наоборот (Д.Векслер, Р.Уайсберг, Г.Айзенк, Л.Термен, Р.Стернберг и др.).

Необходимо отметить что, понятия «творческое мышление» и «креативность», также нуждаются в уточнении, так как в литературе они часто трактуются как сходные понятия. Между тем творческое мышление является психическим процессом, а креативность - обозначается как специфическое качество субъекта, проявляющееся в способности к творческому мышлению и расценивающее как его субъектная, личностная сторона.

Дж.Гилфорд под креативностью понимает способность человека отказаться от стереотипных способов поведения и действий, основу которой составляет дивергентное мышление, «идущее в разных направлениях», допускающее варьирование путей решения проблемы, приводящее к неожиданным выводам и результатам.

Среди тестов, изучающие мышления, особым местом пользуется Гилфорда, направленные на изучения творческого потенциала личности. Автор тестов, выделяя дивергентное и конвергентное мышление, замечает, что в си- 
туациях определенности проявляется аналитическое мышление, а дивергентное мышление необходимо в решении проблем, имеющих многочисленные правильные ответы (Туник 2002). Некоторые авторы рассматривают креативность как способность порождать нестандартные нетрадиционные идеи, а дивергентному мышлению отводят роль составной части креативности.

Х.Е.Трик, определяя креативность как процесс, в результате которого создается ранее не существовавшее, подчеркивает, что креативность это продукт, процесс, способность и черта личности в целом (Психология мышления 2008: 357).

Дополняя эту точку зрения, Торенс считает, что креативность проявляться, когда информации включаются в новые структуры в процессе поиска новых решений. Показательно также высказывание по этому вопросу Джонсона (1973), который креативность объясняет как полезный, эффективный самопроизвольный акт, в процессе социального взаимодействия. Э. де Боно под креативностью подразумевает "создание новых идей", "поведение в самообразующейся информационной системе, которое создает ассиметричные модели" (Боно 2005:92). По мнению M.Wallach, Н.Роджерс, порождение оригинальных идеи в условиях разрешения и постановки новых проблем, обнаружение необычных способов выражения - есть проявления креативности (Wollach, Kogan 1965).

Один из современных подходов к вопросу креативности является «теория инвестирования», Р.Стернберга и Д.Лаверта. Согласно этой теории, креативность - это способность «покупать идеи по низкой цене и продавать по высокой» (Sternberg 1985).

При этом под “идеей покупать" авторы имеют в виду умения личности схватить, правильно воспринимать и точно оценить ресурс и возможность развития еще нераспростра- ненных, недоказанных идей, а после их осуществления и сбыта на “рынке" воплощать другие идеи.

Отдельные авторы, в частности Стернберг, полагают, что неосуществление личностью своего творческого потенциала происходит, если личность выдвигает свои представления, намерение или замыслы несвоевременно или если эти идеи представляются слишком поздно, однако, здесь нужно учесть, что творчество заменяется его социальной оценкой и признанием. Стернберг обращает внимание на тот факт, что творческие проявления определяются шестью основными факторами: 1) интеллектом как способностью; 2) знанием; 3) стилем мышления; 4) индивидуальными чертами; 5) мотивацией; 6) внешней средой.

В связи со сказанным, Дружинин справедливо замечает, что интеллектуальную способность Стернберг расценивает как базовую. Между тем для творческого процесса имеют существенное значение такие компоненты интеллекта, как: 1) синтетическая способность новое видение проблемы, преодоление границ обыденного сознания; 2) аналитическая способность - выявление идей, достойных дальнейшей разработки; 3) практические способности - умение убеждать других в ценности идеи («продажа»)(Дружинин В. 2001).

Если у личности доминирует аналитическая способность, утверждает Стернберг, то он скорее становиться хорошим экспертом или критиком, но в процессе творения и создания нового имеет трудности. Синтетическая способность проявляется умением выдвигать много оригинальных идей, но при отсутствии аналитической способности они становятся ненужными и бесплодными. Наличие же практической способности без вышеуказанных двух часто приводит к “некачественной” продаже уже имеющихся идей. 
Для творческого проявления также немаловажную роль играют наличие знания и независимость мышления. Чтобы знания играли позитивную роль, человек должен ясно представлять шаги своих действий, очертить поле своего потенциала и, проявляя креативность, выйти за его пределы, однако часто устаревающие знания мешают смотреть на проблемную ситуацию новым свежим взглядом.

Творческий процесс осуществляется также при наличии типа мышления свободного от стереотипов и ригидных установок, умении идти на целесообразный риск, готовность преодолевать трудности, на наличии внутренней мотивации, терпимости к неопределенности, независимости от внешнего влияния. Стернберг для проявления творческого потенциала отводит важное место творческой среде и мотивации, подчеркивая, что все эти звенья взаимодействуют и комплексный результат от их взаимодействия несводим к влиянию какоголибо одного из них, так как мотивация может возместить отсутствие творческой среды, а интеллект, взаимодействуя с мотивацией, значительно повышает степень проявления креативности.

Изучение креативности сопряжено с большими трудностями, которые возникают, главным образом, в связи с ее рассмотрением вне целостной структуры личности и вне ее жизненных целей. В настоящее время можно выделить несколько подходов к пониманию феноменов креативности. Среди них креативность:

- как особенность интеллекта, как отражение уровня или свойства мышления;

- как способность интеллекта;

- как потребность личности в поисковопреобразовательной деятельности при условии активного взаимодействия со средой;

- $\quad$ как свойство целостной личности .
Среди указанных подходов только последний включает креативность в целостную структуру личности. Сегодня важной и актуальной научной задачей является поиск путей исследования креативности, творческого мышления в единстве не только когнитивных и личностных, но и адаптационных и проявлений в условиях изменяющейся действительности, ускорения темпа жизни, в связи с чем видоизменяются и значительно усложняются конфликтные ситуации жизнедеятельности, а так же требования и условия разрешения различных проблемных и конфликтных ситуаций.

Анализируя соотношение понятий «мышление» и «интеллект», отметим, что мышление и интеллект - сходные по содержанию термины. Дружинин, сравнивая понятия «ум» и «интеллект», объясняет это следующим образом: «интеллекту в обыденном понимании соответствует слово «ум», который выражает свойство, способность, а мышлению - «обдумывание» как процесс». Таким образом, интеллект рассматривается как способность к мышлению, а мышление - как процесс реализации интеллекта. Вместе с тем он подчеркивает, что «мышление тесно связано с открытием нового, с творчеством. Однако творчество не может быть отождествлено с мышлением. Мышление - это один из видов познания, творчество же возможно не только в познании» (Дружинин 2001: 153).

В современной психологической литературе интеллект определяется как интеграция всех познавательных процессов под доминирующим влиянием мышления. Развивая эту идею, можно предположить, что творческое мышление, являясь синтетической и высшей формой развития мышления, является инструментом этой интеграции, средством систематизации и взаимного включения психических функций друг в друга. А это, в свою очередь, обозначает адаптивную природу творческого мышления. 
В российской психологической науке исследования мышления традиционно рассматриваются в процессуально-деятельностной парадигме (Л.С.Выготский, А.Н.Леонтьев, С.Л.Рубинштейн, П.Я.Гальперин, А.В.Брушлинский, Н.Ф.Талызина, О.К.Тихомиров, Абульханова-Славская К.А. и др.). Однако, по мнению Я.А.Пономарева, исследование творчества является комплексной проблемой, которая не получила еще подлинного развития, и большинство эмпирических исследований проводится без должного учета условий и контекста его развития (Пономарев Я. А. 1976: 31).

Концепции и теории о творческом мышлении в психологии представлены в отдельных аспектах, в частности, творческое мышление рассматривается как предпосылка научной деятельности и деятельности, творческое мышление как особый вид одаренности, творческое мышление как специфическая интеллектуальная деятельность. Следует отметить, что имеется определенная двойственность в понимании характеристик в структурированности знаний о творческом мышлении, что приводит, с одной стороны, к выделению определенных критерий творческого мышления и отождествлению его с понятием творчества (Г.С.Альтшуллер, Н.Н.Вересов, И.П.Волков, Я.Л.Пономарев), и с другой стороны - к рассматриванию творческого мышления с диаметрально противоположных концепций (М.С.Бернштейн, Э.Боно, И.Н.Семенов).

Другой ученый, Терстоун, обратил внимание на слабую связь творческих способностей со способностями к обучению и интеллектом, он указал на взаимосвязь творческой активности с особенностями темперамента и способностью быстро усваивать и порождать идеи.

Наиболее системный подход к вопросу творческого мышления в современной психологии отражает теория Л.М.Веккера, которая, рассматривая мышления как познавательный процесс, выделяет такие ее свойства, как: 1) особая пространственно-временная структура, 2) особая модальность, 3) особая интенсивность (Веккер 1998).

Обобщая подход Л.М.Веккера о неограниченности пространственно-временных свойств мышления, указывая на интермодальную природу мышления и на взаимозависимость интенсивности мышления от энергетической мобилизацией нервной системы субъекта, Дружинин делает вывод, что творческое мышление также обладает такими характеристиками, а именно «максимальной свободы в преодолении пространства и времени и в оперировании ими при решении конкретных задач» максимальная обобщенность по отношению к конкретным образам и сенсорным переживаниям, и основано на максимальной субъективной активации (Дружинин 2001).

Л.М.Веккер указывает также на специфические свойства мысли как психического образования. Так, мысль характеризуется «феноменом понимания» - целостным охватом проблемной ситуации и экстраполяцией условий ситуации при прогнозировании, опосредованностью, обобщенностью, т.е. каждая мысль является синтетической по сути. При этом для мысли характерны децентрация, т.е. внутренний отход носителя от субъектности мысли, понятийность, обратимость, т.е. возможность любых переходов в системе «операции действия - деятельность», фигуративность (выводимость новых форм мысли из имеющихся). Кроме того, мысль облекается в речевую форму, а проблемная ситуация выступает ее стимулом (Веккер 1998 ).

Вместе с тем Л.М.Веккер подчеркивает, что для мысли одновременно свойственны, как «феноменом понимания», также децентрация, понятийность, обратимость, фигуративность, и проблемная ситуация в этом случае является толчком для оформления мысли в ре- 
чевую форму. Все эти свойства максимально выражены и могут быть однозначно соотнесены к творческой мысли.

Согласно концепции Л.М.Веккера, творческое мышление зависит от сбалансированного сочетания персеверативных и ассоциативных механизмов, при этом «продуктивность мышления зависит не только от его качественно специфичных свойств (например, от уровня развития мыслительных операций), но и от степени связи мышления с другими когнитивными процессами, от глубины интеграции мышления в структуру познавательных функций в целом» (Веккер 1998: 111).

Если приложить перечисленные свойства мысли вообще к мысли творческой, то станет ясно, что она обладает ими в максимальной степени: творческая мысль невозможна без феномена инсайта (наиболее яркий случай феномена понимания, мгновенного и целостного охвата ситуации), она всегда направлена на прогнозирование ситуации (экстраполяция и антиципация), стремится к максимальному обобщению условий задачи, эффективна только при полном преодолении эгоцентризма мышления (максимальная децентрация), протекает за счет постоянной обратимости и оценивается по своей продуктивности.

Основываясь на теории Л.М.Веккера, можно сделать вывод о том, что творческое мышление обладает определенными свойствами, не является видом мышления в целом, а представляет собой его высшую форму.

Подобного взгляда придерживается А.В.Брушлинский, который считает, что любое мышление у любого человека всегда, хотя бы в минимальной степени, является самостоятельным, открывающим нечто существенно новое. А потому творческое и продуктивное мышление - это, по мнению А.В.Брушлинского, тавтология (типа «красивая красавица»), а репродуктивное мышление - противоречие в определении (типа «жареный лед»). Субъект, в своей деятельности, духовности и т. д. - это субъект творчества, созидания, инноваций. Любая его деятельность (хотя бы в минимальной степени) является творческой и самостоятельной (Рубинштейн 1958: 147).

Необходимо отметить что, что многие авторы М.Вертгеймер, К.Дункер, О.Зельц, Р.Солсо, рассматривающие такие «виды» мышления, как дивергентное, версионное, гипотетическое, продуктивное, расценивают их именно как формы продуктивного развития. В этом ряду творческое мышление также необходимо считать высшей формой развития мышления.

Как считает Брунер, творческое мышление у определенных людей обуславливает неспецифическим типом программирования информации. Голлах и Коган (Wollach, Kogan 1965) экспериментально доказывали, что высококреативные дети имеют способность к более расширенным категоризациям, следовательно, познавательная сфера креативных индивидов характеризуется наличием широких категорий, синтетичностью в восприятии окружающего мира и высоким уровнем когнитивной гибкости.

Нужно отметить, что исследователи по данной проблеме ведут поиск суммарного показателя, обрисовывающего творческую личность. В частности, Д.Б. Богоявленская считает, что показатель - может определяться как некоторое сочетание интеллектуальных и мотивационных факторов. А.В.Брушлинский же рассматривает как непрерывное единство процессуальных и личностных компонентов мышления вообще и творческого мышления в частности. Таким образом, творческое мышление это одновременно и дивергентное, и версионное, и гипотетическое, и продуктивное мышление, это наиболее зрелая стадия развития мышления.

Обзор наиболее известных определений «творчества», «творческого мышления», «интеллекта» и «креативности» приводит нас к 
выводу, что специфичность понятия «творчество» заключается в том, что это особый целостный вид деятельности, включающий все необходимые компоненты (мышление, мотивацию, способности...), обуславливающий общее развитие личности, ее вклад в историю человечества (Л.С.Выготский, С.Л.Рубинштейн, А.В.Брушлинский, В.В.Давыдов и др.). В то время как термин "креативность" связывают с особенностями мышления, совокупностью способностей, позволяющих генерировать идеи, отличающиеся от общепризнанных, стереотипных. Таким образом, креативность есть особая творческая способность к продуцированию новых нестандартных, оригиналь-

\section{ЦИТИРУЕМАЯ И УПОМЯНЫТАЯ ЛИТЕРАТУРА}

1. Богоявленская, Д.Б. (1971). «Метод исследования уровней интеллектуальной активности». Вопросы психологии. № 1.

2. Богоявленская, Д.Б. (1983). Интеллектуальная активность как проблема творчества. Ростов-на-Дону.

3. Боно, Э. (2005). Серьёзное творческое мышление Пер.с англ. Д.Я.Онацкая. Минск.

4. Веккер, Л.М. (1998). Психика и реальность. Единая теория психических процессов. Москва.

5. Дружинин, В. (2001). Психология. Учебник для гуманитарных вузов. СПб., Питер.

6. Пономарев, Я. (1976). Психология творчества. М.

7. Психология мышления. (2008). под. ред. Ю.Б.Гиппенрейтер, В.А.Спиридонова, М.В.Фаликман, В.В.Петухова. М. ных образов, идей, гипотез (Дж.Гилфорд, П.Торранс, В.Н.Дружинин и др.). В то же время творческое мышление, являясь интегратором интеллекта, обобщенным и высшим свойством мышления, средством систематизации и взаимовключения психических функций друг в друга, следует рассматривать как высшую ступень развития мышления, как процесс, который обеспечивается способностью личности к творчеству в качестве креативности. Это подчеркивает адаптивную природу творческого мышления - оно является необходимым условием полноценного развития всей системы интеллектуальных функций человека.

8. Рубинштейн, С.Л. (1958). О мышлении и путях его исследования. М.

9. Тихомиров, О.К. (1975). Психологические исследования творческой деятельности. M.

10. Туник, Е.Е. (2002). Психодиагностика творческого мышления. Креативные тесты. СПб.

11. Sternberg, R. (1985). General intellectual ability // Human abilities by R. Sternberg. San Francisco: Freeman.

12. Torrance, E.P. (1965). Scientific views of creativity and factors affecting its growth // Daedalus: Creativity and Learning. Boston: Houghton Mifflin.

13. Wollach, M.A.; Kogan N.A. (1965) "A new look at the creativity - intelligence distinction". Journal of Personality. № 33. 


\section{ТВОРЧЕСКОЕ МЫШЛЕНИЕ В СИСТЕМЕ ПОНЯТИЙ СОВРЕМЕННОЙ психологии}

\section{PEЗЮME}

В статье с точки зрения современных теоретических подходов рассматриваются и анализируются такие понятия как "творчество», «мышление», «творческое мышление», «интеллект», «креативность». Подчеркивается необходимость систематизации этих понятий, поскольку значительная неопределенность в их употреблении, создает затруднения при их использовании и создании единой концепции творческого мышления. Обосновывается подход, согласно которому творческое мышление необходимо рассматривать не в качестве одного из видов, а как высшую ступень развития мышления. С этой точки зрения творческое мышление становится интегратором интеллекта и необходимым условием развития всей системы интеллектуальных функций.

Ключевые понятия: мышление, творчество, интеллект, креативность, творческий процесс, творческие способности.

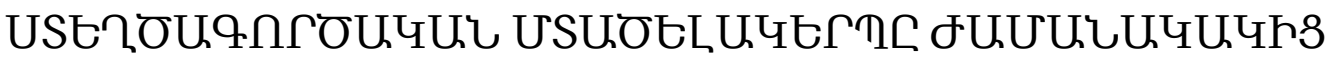

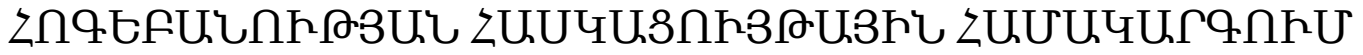

\section{UUФПФกЋU}

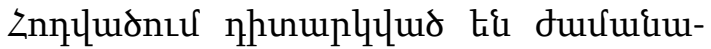

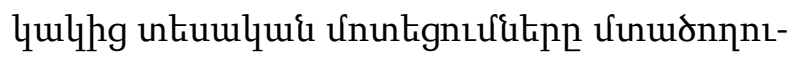

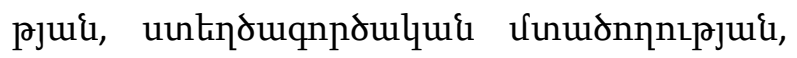

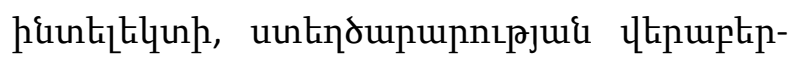

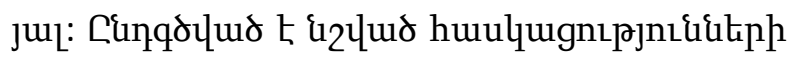

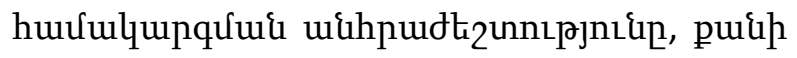
np npuigg lhpunduif hupgnıर्य unlqu uin-

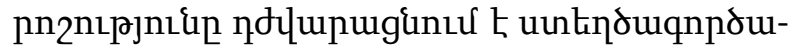

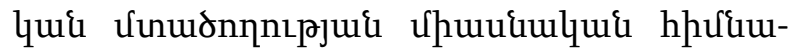

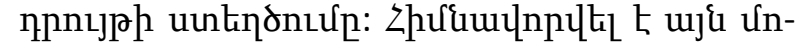

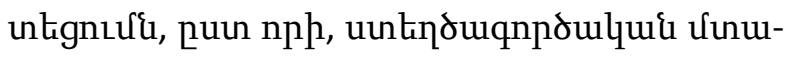

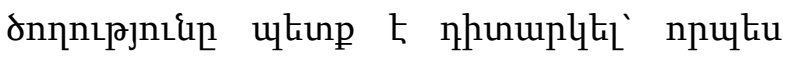

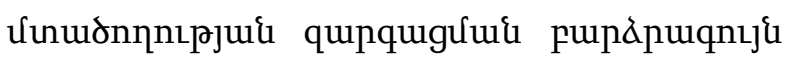

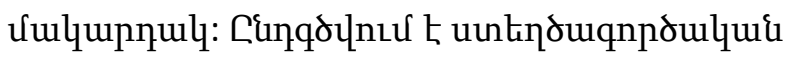

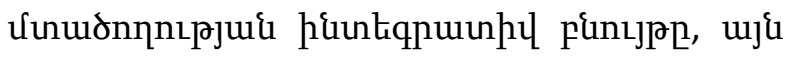
huintiu $\mathrm{t}$ quihu npultu hiuntililunnıul

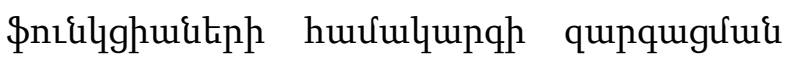
wihpudtizn ưujưu: 


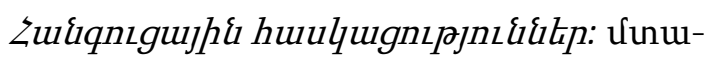

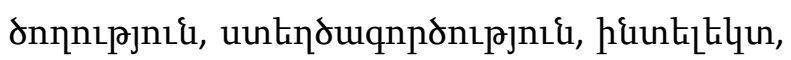

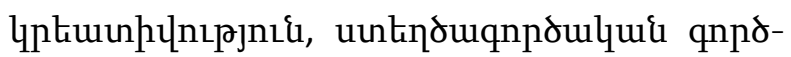

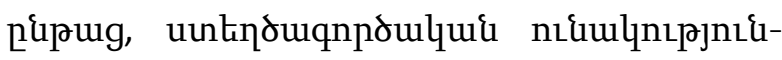
quip:

HAROYAN NELLY

TEVOSYAN MARIA

\section{CREATIVE THINKING IN THE SISTEM OF CONCEPTS OF MODERN PSYCHOLOGY}

\section{SUMMARY}

Modern theoretical approaches related to thinking, creative thinking, intellect, creativity are observed in the article. The necessity of coordinating the mentioned concepts is highlighted since the uncertainty existing in their application hinders the creation of the joint postulate of creative thinking. The approach according to which creative thinking should be observed as higher level of creative thinking development, has been grounded. The integrative nature of creative thinking is emphasized, it is shown as a necessary condition for the development of the intellectual function system.

Key concepts: thinking, createvity, intelligence, creativity, creative process, creative ability. 